\title{
Выращивание и свойства изопараметрических гетероструктур InAIGaPAs/GaAs
}

\author{
(С) Д.Л. Алфимова ${ }^{1}$, Л.С. Лунин ${ }^{1,2}$, М.Л. Лунина ${ }^{1}$, Д.А. Арустамян ${ }^{2}$, \\ А.Е. Казакова ${ }^{2}$, С.Н. Чеботарев ${ }^{1,2}$ \\ ${ }^{1}$ Южный научный центр Российской академии наук, \\ 344006 Ростов-на-Дону, Россия \\ ${ }^{2}$ Южно-Российский государственный политехнический университет (НПИ) им. М.И. Платова, \\ 346428 Новочеркасск, Россия \\ E-mail: lunin_Is@mail.ru
}

(Получена 28 декабря 2016 г. Принята к печати 28 фревраля 2017 г.)

Обсуждаются результаты выращивания изопараметрических гетероструктур InAlGaPAs/GaAs. Исследованы состав, кристаллическое качество и люминесцентные свойства гетероструктур.

DOI: 10.21883/FTP.2017.10.45025.8511

\section{1. Введение}

Использование пятикомпонентных твердых растворов (ПТР) соединений $\mathrm{A}^{\mathrm{III}} \mathrm{B}^{\mathrm{V}}$ позволяет независимо регулировать период решетки, ширину запрещенной зоны и коэффициент термического расширения (КТР) [1]. Это создает предпосылки для получения на основе бинарных соединений изопараметрических (изопериодических и согласованных по КТР) гетероструктур, работающих в более широком спектральном диапазоне, чем в случае четырехкомпонентных твердых растворов [2]. Указанные возможности открывают принципиально новые перспективы для создания оптоэлектронных устройств и приборов. Применение подобных гетероструктур в оптоэлектронике выдвигает повышенные требования к их составу и кристаллическому качеству [3-6].

Известна технология получения многокомпонентных гетероструктур на основе соединений $\mathrm{A}^{\mathrm{III}} \mathrm{B}^{\mathrm{V}}$ методом молекулярно-лучевой эпитаксии, осаждения из газовой фазы с использованием металлоорганических соединений, ионно-лучевого осаждения [7-10]. Однако эти методы связаны с большими энергозатратами, поскольку применяемые кассеты, тигли и нагревательные устройства позволяют использовать в одном технологическом процессе ограниченное количество пластин подложек. Поэтому длительность технологического процесса эпитаксии образцов существенно возрастает. Кроме того, указанные методы используют сложное и дорогостоящее оборудование. Одним из доступных методов получения гетероструктур продолжает оставаться эпитаксия из жидкой фазы (ЖФЭ) [11]. Несмотря на ряд преимуществ метода ЖФЭ, получение этим методом многокомпонентных гетероструктур соединений $\mathrm{A}^{\mathrm{III}} \mathrm{B}^{\mathrm{V}}$ контролируемого состава затруднено в связи с изменением температуры в процессе роста. Кроме того, жидкофазные методы требуют значительного расхода дорогостоящих металлов (индия, галлия), так как приготовленный раствор пригоден только для разового использования. Метод зонной перекристаллизации градиентом температуры (ЗПГТ) экономичен, так как не требует большого количества исходных материалов за счет небольших толщин зон и неоднократного использования одного и того же расплава [12]. В методе ЗПГТ путем программного изменения параметров процесса можно управлять свойствами и кристаллическим качеством многокомпонентных гетероструктур соединения $\mathrm{A}^{\mathrm{III}} \mathrm{B}^{\mathrm{V}}[13,14]$.

Целью настоящей работы являлось выращивание изопараметрических гетероструктур InAlGaPAs/GaAs и исследование их свойств.

\section{2. Теоретический анализ}

Для расчета периода кристаллических решеток $\operatorname{In}_{x} \mathrm{Al}_{y} \mathrm{Ga}_{1-x-y} \mathrm{P}_{z} \mathrm{As}_{1-z} a(x, y, z)$ и ширины запрещенной зоны $\left(E_{g}\right)$ использовали уравнения работ $[15,16]$.

В гетероструктурах $\operatorname{In}_{x} \mathrm{Al}_{y} \mathrm{Ga}_{1-x-y} \mathrm{P}_{z} \mathrm{As}_{1-z} / \mathrm{GaAs}$ даже при незначительном увеличении концентрации индия $x$ изопериодические линии резко смещаются в область больших концентраций фосфора $z$ (рис. 1). Это весьма важно, так как в четырехкомпонентном твердом растворе AlGaPAs количество фосфора, необходимое для согласования параметров решеток эпитаксиального слоя и подложки GaAs, мало́ (линия, соответствующая $x=10^{-5}$ ), коэффициент распределения фосфора велик, а следовательно, выращивание методом ЗПГТ без подпитки сопряжено со значительными трудностями. Поэтому для варьирования состава твердой фазы необходима подпитка жидкой фазы сильно сегрегирующими компонентами, например, P и Al. Для рассматриваемой гетероструктуры изопериодические линии описываются зависимостью типа $z=A+B y$ в пределах значения $y$ от 0 до некоторого $y_{\max }$. Величина $y_{\max }$ уменьшается с увеличением концентрации индия $x$. Область изопериодических составов по $y$ также сужается с ужесточением требований к степени согласования КТР слоя и подложки. Изложенное иллюстрируется данными, приведенными в табл. 1. Расчеты показали, что обычно КТР $(\alpha)$ ПТР меньше такового для $\mathrm{GaAs}$, причем разность в КТР увеличивается по мере удаления состава твердого раствора от состава бинарного соединения. Если 


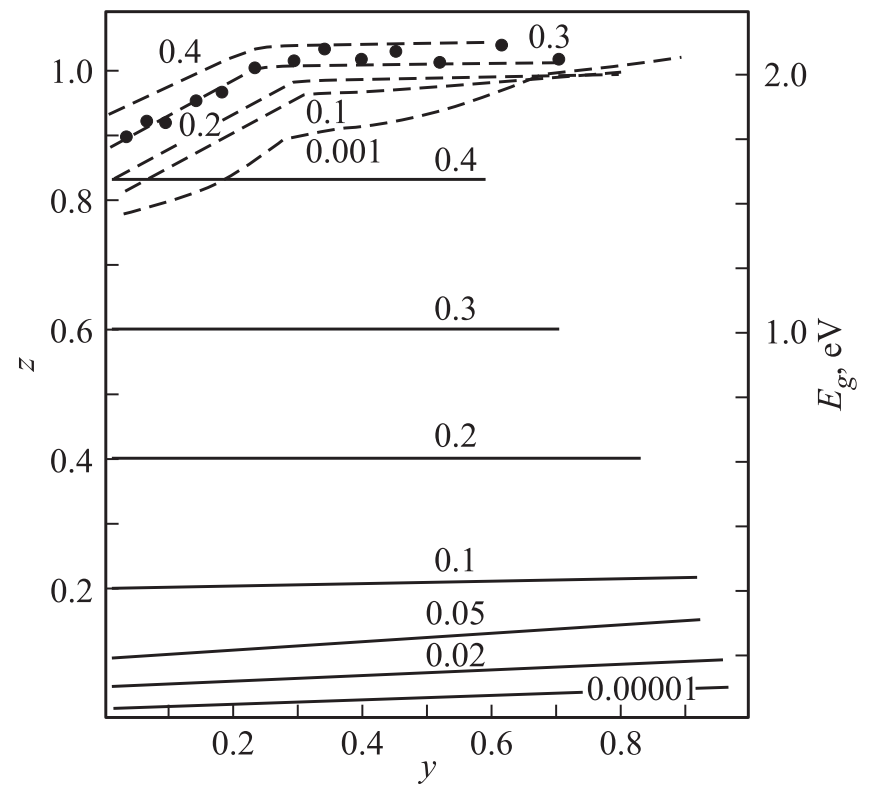

Рис. 1. Концентрационные зависимости: изопериодических линий (сплошные линии, левая шкала), ширины запрещенной зоны (штриховые, правая шкала). Значения параметра $x$ указаны у кривых, точки - экспериментальные данные.

разность $\delta \alpha=0.2$, то охлаждение гетероструктуры от температуры эпитаксии $\sim 1100 \mathrm{~K}$ до комнатной температуры приводит к возникновению разности параметров решеток $a$ подложки и слоя $<0.1 \%$. Видно, что с увеличением $x$ все более узкий интервал составов соответствует приемлемому согласованию слоя с подложкой по КТР. При выборе составов твердых растворов следует остановиться на тех, которые по параметрам решетки согласованы с подложкой при комнатной температуре. Отличие величин КТР $\alpha_{0}$ и параметра решетки $a_{0}$ для составов твердого раствора от таковых для подложки, $\alpha_{s}$ и $a_{s}$, оцениваем величинами $\delta \alpha=\left(\alpha_{0}-\alpha_{s}\right) / \bar{\alpha}$ и $\delta a=\left(a_{0}-a_{s}\right) / \bar{a}$. В табл. 1 приведены данные составов, при которых не будет возникать интенсивное дефек-

Таблица 1. Интервалы изопериодичности $\left(y_{\max }\right)$ при различных $\delta \alpha$ и параметры прямых $z=A+B y$ при фиксированных значениях $x$ для гетероструктуры $\mathrm{GaAs} / \mathrm{In}_{x} \mathrm{Al}_{y} \mathrm{Ga}_{1-x-y} \mathrm{P}_{z} \mathrm{As}_{1-z}$ (во всех случаях $y_{\min }=0$ ).

\begin{tabular}{l|c|c|c|c}
\hline \multirow{2}{*}{$x$} & \multicolumn{2}{|c|}{$y_{\max }$} & \multirow{2}{*}{$A$} & $B$ \\
\cline { 2 - 3 } & $\delta \alpha=0.05$ & $\delta \alpha=0.2$ & & \\
\hline 0 & 0.16 & 0.80 & 0 & 0.0422 \\
0.02 & - & - & 0.0398 & 0.0413 \\
0.04 & - & - & 0.0797 & 0.0394 \\
0.05 & 0.10 & 0.72 & 0.0996 & 0.0387 \\
0.1 & 0.0 & 0.65 & 0.1994 & 0.0339 \\
0.2 & 0.0 & 0.47 & 0.3994 & 0.0231 \\
0.3 & 0.0 & 0.26 & 0.5999 & 0.0098 \\
0.4 & 0.0 & 0.05 & 0.8118 & 0.0063
\end{tabular}

Таблица 2. Типы переходов в гетероструктуре GaAs/ $\mathrm{In}_{x} \mathrm{Al}_{y} \mathrm{Ga}_{1-x-y} \mathrm{P}_{z} \mathrm{As}_{1-z}$

\begin{tabular}{c|c|c}
\hline $\begin{array}{c}\text { Предел } \\
\text { изменения } x\end{array}$ & $\begin{array}{c}\text { Предел } \\
\text { изменения } y\end{array}$ & $\begin{array}{c}\text { Тип } \\
\text { переходов }\end{array}$ \\
\hline 0.0 & $0 \leq y \leq 0.3$ & $\Gamma$ \\
& $0.3 \leq y \leq 0.58$ & $L$ \\
& $0.58 \leq y \leq 1.0$ & $X$ \\
0.1 & $0 \leq y \leq 0.38$ & $\Gamma$ \\
& $0.38 \leq y \leq 0.9$ & $X$ \\
0.2 & $0 \leq y \leq 0.32$ & $\Gamma$ \\
& $0.32 \leq y \leq 0.8$ & $X$ \\
0.3 & $0 \leq y \leq 0.32$ & $\Gamma$ \\
& $0.32 \leq y \leq 0.7$ & $X$ \\
0.4 & $0 \leq y \leq 0.26$ & $\Gamma$ \\
& $0.26 \leq y \leq 0.6$ & $X$
\end{tabular}

тообразование в процессе роста. На рис. 1 приведены зависимости ширины запрещенной зоны $E_{g}$ от составов (штриховые линии). Видно, что $E_{g}$ растет с увеличением $y$ для данного $x$.

Ширина запрещенной зоны твердого раствора всегда больше таковой для подложки GaAs, причем одному и тому же значению $E_{g}$ соответствует множество изопериодных составов. Характерным для твердого раствора InAlGaPAs является наличие прямых и непрямых переходов, тип которых определяется составом (табл. 2).

\section{3. Экспериментальная часть}

Выращивание гетероструктур InAlGaPAs/GaAs осуществлялось методом ЗПГТ [12]. В качестве подложечного материала использовались монокристаллические пластины арсенида галлия, как не легированные (АГЧ), так и легированные $\mathrm{Si}$ до концентрации $n=(1-5) \cdot 10^{18} \mathrm{~cm}^{-3}$ (n-типа) и $\mathrm{Zn}$ до концентрации $(1-8) \cdot 10^{18} \mathrm{~cm}^{-3}$ ( $p$-типа).

Диаметр пластин составлял 50 мм с ориентацией по плоскостям (100) и (111). Пластины, предварительно отшлифованные и полированные до 14-20 класса чистоты, подвергались химическому травлению для удаления поверхностного наружного слоя. Обработка проводилась в травителях: $\mathrm{HCl}: \mathrm{CrO}_{3}=3: 1$ или $\mathrm{H}_{2} \mathrm{SO}_{4}: \mathrm{H}_{2} \mathrm{O}_{2}: \mathrm{H}_{2} \mathrm{O}=3: 1: 1$.

Толщина подложки после обработки составляла 400-450 мкм. Далее эти пластины промывались в дистиллированной воде и обрабатывались в парах толуола для удаления остатков органических веществ. Обработанные таким образом подложки арсенида галлия загружались в технологическую кассету. Данная операция проводилась в специальном пыленепропускаемом боксе в очищенной от пыли атмосфере. В случае проведения ЗПГТ используется подпитывающая твердая фаза. В качестве подпитки использовались пластины InP, GaP, 
GaAs при выращивании тонких слоев (<10 мкм). Для получения толстых слоев твердых растворов InAlGaPAs (> 10 мкм), необходимых, например, для полупроводниковых детекторов излучения, применялись предварительно синтезированные поликристаллы InAlPAs, coдержащие компоненты с большим коэффициентом распределения (Al, P). Поликристаллы получали следующим образом: из упрочненного графита изготавливали контейнер диаметром 50 мм, высотой 200 мм с плотно прилегающей графитовой крышкой. Вычисляли (в соответствии с необходимым составом твердой фазы получаемых слоев) и готовили навески компонентов, составляющих шихту для получения поликристалла. Общая масса расплава рассчитывалась в соответствии с объемом предполагаемого слитка поликристалла. После химической обработки компоненты шихты помещались в контейнер. Контейнер помещался в установку для вытягивания монокристаллов бинарных соединений $\mathrm{A}^{\mathrm{III}} \mathrm{B}^{\mathrm{V}}$ c резистивным нагревом печи. Контейнер с шихтой нагревался и выдерживался в течение нескольких минут при температуре чуть выше температуры плавления $(\sim 1773 \mathrm{~K})$. Потом следовало резкое отключение нагревательных элементов и жидкий расплав кристаллизовался. Полученный слиток поликристалла резали на пластины толщиной 500-600 мкм. Толщина галлиевой зоны $(l)$ изменялась от 10 до 200 мкм. Сандвичи $\mathrm{GaAs}-\mathrm{Ga}-\langle$ поликристалл InAlGaPAs〉 помещали в камеру, которую откачивали до $10^{-3}$ Па, а затем наполняли водородом до 0.5 Па, процесс ЗПГТ проводили в потоке водорода. Гетероструктуры InAlGaPAs/GaAs выращивали при температурах $837 \leq T \leq 937 \mathrm{~K}$ и градиентах температуры $10 \leq G \leq 30 \mathrm{~K} / \mathrm{cm}$. Выбор температурного режима осуществлялся путем исследования температур ликвидуса для каждого отдельного состава с помощью установки визуально-термического анализа in situ по методике [17].

Исследование морфологии поверхности выращенных гетероструктур InAlGaPAs/GaAs проводили на атомносиловом микроскопе Solver HV и сканирующем микроскопе Quanta 200.

Определение несоответствия параметров решеток подложки и слоя и оценка кристаллического качества гетероструктур осуществлялись методом регистрации рентгеновской дифракции. Съемка кривых дифракционного отражения (КДО) рентгеновского излучения проводилась на высокоразрешающем рентгеновском дифрактометре ТРС-1 в двухкристальной геометрии с использованием линии излучения меди. Помимо изменения параметра решетки $\Delta a$ определяли и анализировали полуширины КДО от эпитаксиального слоя и подложки. Учитывались также форма дифракционных кривых и наличие (отсутствие) интерференционных максимумов, несущих информацию о качестве поверхности слоя и планарности границы раздела слой/подложка.

Состав полученных твердых растворов определяли на рентгеновском микрозондовом анализаторе „Саmebax“ при ускоряющем напряжении 20 кВ и токе первичного пучка $0.1-1.0$ мкА. Погрешность измерений составляла $\pm 0.01 \%$ для тяжелых элементов (с атомным номером более 25$), \pm 0.1 \%$ для легких элементов (Р) при содержании элемента в образце в количестве 0.1 мол. доли.

Измерения фотолюминесценции проводили в спектральном диапазоне от 950 до 1500 нм при температуре $300 \mathrm{~K}$ и в жидком азоте при $77 \mathrm{~K}$ в криостате с кварцевыми окнами. В качестве источника возбуждающего оптического излучения использовался инжекционный лазер с длиной волны 402 нм и мощностью излучения $8.5 \mathrm{MB}$, фотодетектором служил германиевый фотодиод ФПУ ФДГ с рабочим спектральным диапазоном длин волн от 0.5 до 2 мкм. Возбуждение фотолюминесценции осуществлялось со стороны эпитаксиальных слоев.

\section{4. Экспериментальные результаты и их обсуждение}

При выращивании твердого раствора $\mathrm{In}_{x} \mathrm{Al}_{y} \mathrm{Ga}_{1-x-y} \mathrm{P}_{z} \mathrm{As}_{1-z}$ с подпиткой из поликристаллаисточника InAlPAs слои однородны по составу, за исключением переходной области толщиной $h$ (рис. 2, кривые 1-4 для Al, 5 для As) вблизи старта зоны. Можно подобрать такую начальную добавку компонента в жидкой фазе, при которой переходная область практически отсутствует. При этом начальное значение концентрации рассматриваемого компонента в зоне $C_{l}^{\circ}$ должно удовлетворять условию $K_{0} C_{l}^{\circ}=C_{u}^{\circ}$, где $C_{u}^{\circ}-$ концентрация перекристаллизуемого источника, $K_{0}$ - коэффициент распределения компонента на гетерогранице. Рассматриваемый случай иллюстрирует

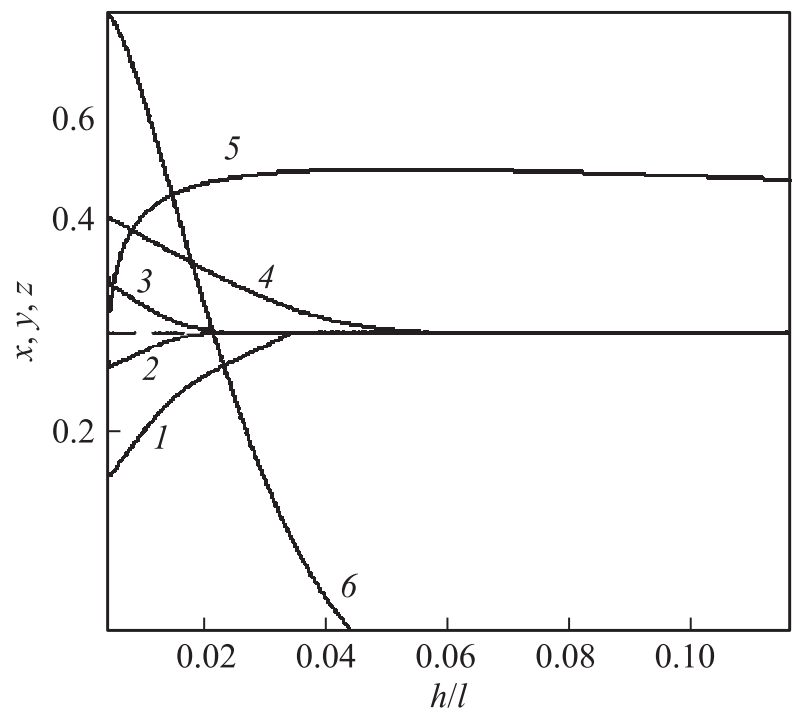

Рис. 2. Распределение компонентов в пятикомпонентном твердом растворе $\operatorname{In}_{x} \mathrm{Al}_{y} \mathrm{Ga}_{1-x-y} \mathrm{P}_{z} \mathrm{As}_{1-z} / \mathrm{GaAs:}$ распределение $\mathrm{Al}(1-4)$ и $\mathrm{As}(5)$ при подпитке из поликристалла $\mathrm{Al}_{0.24} \mathrm{Ga}_{0.76} \mathrm{As} ; 6$ - распределение $\mathrm{P}$ без подпитки. $h / l-$ относительная координата в направлении движения зоны, $h$ и $l$ - толщины слоя и зоны соответственно. 


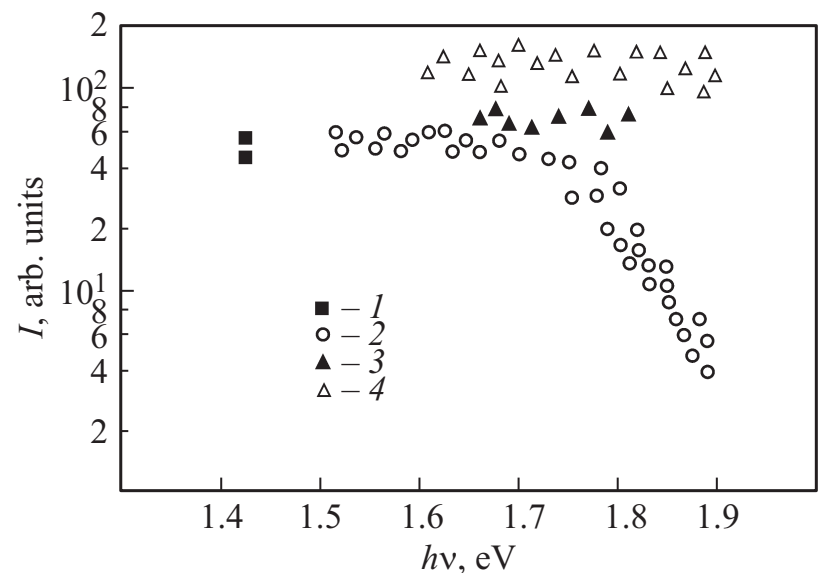

Рис. 3. Зависимость интенсивности фотолюминесценции твердых растворов соединений $\mathrm{A}^{\mathrm{III}} \mathrm{B}^{\mathrm{V}}$ от состава (ширины запрещенной зоны материалов): $1-p$-GaAs, $2-p$-AlGaAs, $3-p$-AlGaPAs, $4-p$-InAlGaPAs.

штриховая прямая на рис. 2. В дальнейшем состав слоя твердого раствора практически повторяет состав источника.

Исследование и анализ люминесцентных свойств ПТР удобно проводить в сравнении со свойствами начиная от бинарных соединений и увеличивая число компонентов до пяти (рис. 3).

Для твердых растворов $\mathrm{AlGaAs}$ в области „прямых“ переходов интенсивность излучения практически постоянна, а дальнейшее увеличение содержания AlAs в твердом растворе вызывает быстрое падение интенсивности излучательной рекомбинации. Физической причиной резкого уменьшения интенсивности излучения в области перехода к „непрямым“ составам является переход электронов из „прямого“ минимума в „непрямой“ и возрастание вследствие этого доли безызлучательной рекомбинации.

Использование четырехкомпонентных твердых растворов, изопериодических бинарным соединениям, позволяет уменьшить влияние дефектности структуры твердого раствора, связанной с несоответствием параметров решеток, сопрягающихся на гетерогранице материалов, и тем самым повысить эффективность излучательной рекомбинации. Как показано на рис. 3, эффективность фотолюминесценции эпитаксиальных слоев AlGaPAs, изопериодических с арсенидом галлия, практически не зависит от состава во всем диапазоне составов твердого раствора. Кроме того, интенсивность излучательной рекомбинации с введением четвертого компонента в аналогичный трехкомпонентный твердый раствор только повышается.

Как показал анализ, введение пятого компонента в соответствующий четырехкомпонентный твердый раствор позволяет получать на основе бинарных подложек строго изопериодические и согласованные по КТР гетероструктуры и сводит до минимума дефектность на гете- рогранице, что влечет за собой значительное повышение эффективности излучательной рекомбинации и улучшение люминесцентных характеристик таких гетероструктур. Экспериментальные исследования (см. рис. 3) показали, что в изопериодических с подложкой пятикомпонентных твердых растворах $\mathrm{In}_{x} \mathrm{Al}_{y} \mathrm{Ga}_{1-x-y} \mathrm{P}_{z} \mathrm{As}_{1-z} / \mathrm{GaAs}$ не наблюдается существенного изменения интенсивности фотолюминесценции при варьировании их состава, если при этом не происходит изменения зонной структуры твердого раствора.

Спектры фотолюминесценции гетероструктур $\mathrm{In}_{x} \mathrm{Al}_{y} \mathrm{Ga}_{1-x-y} \mathrm{P}_{z} \mathrm{As}_{1-z} / \mathrm{GaAs}, \quad$ полученные при 77 и $300 \mathrm{~K}$, приведены на рис. 4. Как видно из рисунка, спектры при $300 \mathrm{~K}$ имеют единственный пик. Люминесценция при $300 \mathrm{~K}$ в основном обусловлена излучением, связанным с краем зоны, ее спектральная форма приближенно описывается выражением $\propto \sqrt{E-E_{g}} \exp \left[\left(E_{g}-E\right) / k T\right]$, где $E$ и $E_{g}-$ энергия фотона и ширина запрещенной зоны соответственно, $k-$ постоянная Больцмана. Спектры люминесценции при $77 \mathrm{~K}$ имеют один пик или сдвоенные пики (рис. 4, штриховые линии). Единичные пики и более интенсивные компоненты сдвоенных пиков также обусловлены испусканием в области края зоны. Эти пики возникают при энергии фотонов на 76-90мэВ выше энергии, соответствующей пикам при $300 \mathrm{~K}$. Подобные сдвиги пиков наблюдались для краев испускания в $\mathrm{AlGaAs}$ при 77 и $300 \mathrm{~K}$. Положение и относительная интенсивность низкоэнергетических спектров со сдвоенными пиками при $77 \mathrm{~K}$ оставались постоянными при изменении интенсивности возбуждения. Интенсивность этих пиков увеличивалась с ростом концентрации In (и, следовательно, Р) и $\mathrm{Al}$, как это показано в спектрах $a$ и $b$. Эти результаты позволяют сделать предположение, что низкоэнергетическое излучение обусловлено не случайными примесями, а некоторыми комплексными центрами, с которыми связаны $\mathrm{Al}$, In и $\mathrm{P}$.

Исследования показали, что в пятикомпонентных твердых растворах неоднородность состава приводит

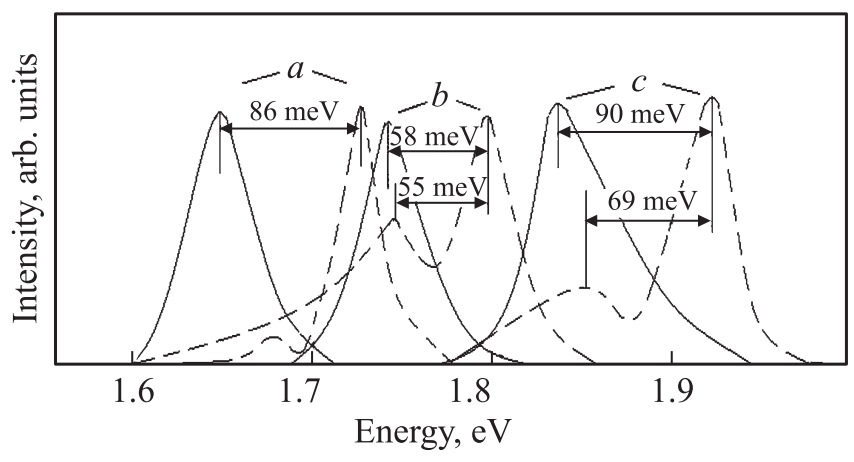

Рис. 4. Спектры фотолюминесценции при 300 (сплошная линия) и $77 \mathrm{~K}$ (штриховая) эпитаксиальных слоев $\mathrm{In}_{x} \mathrm{Al}_{y} \mathrm{Ga}_{1-x-y} \mathrm{P}_{z} \mathrm{As}_{1-z}$, выращенных на подложке GaAs. $a-x=0.010, y=0.16, z=0.022 ; b-x=0.052, y=0.24$, $z=0.06 ; c-x=0.012, y=0.32, z=0.03$. 


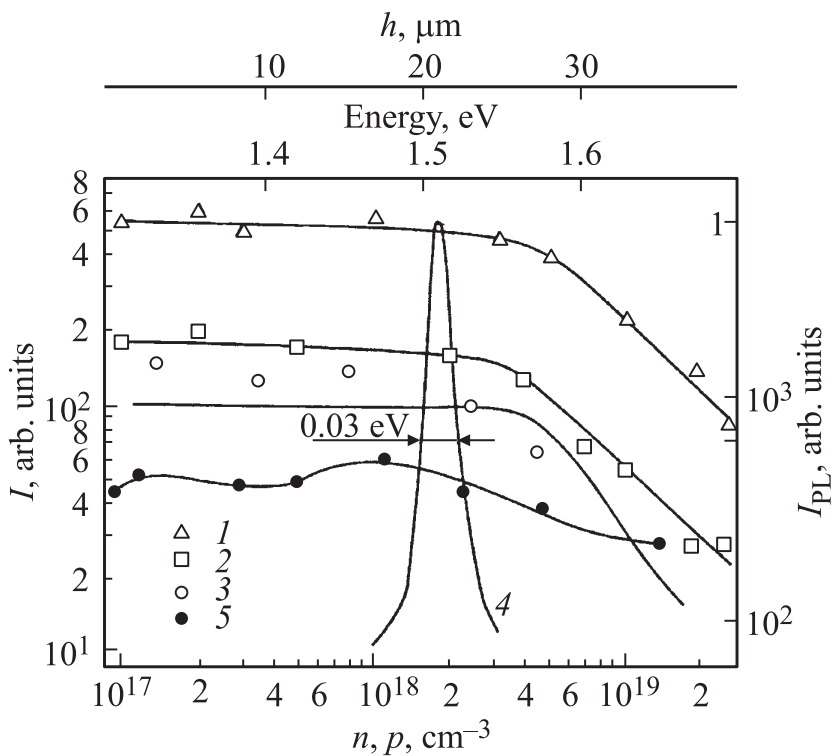

Рис. 5. Зависимости интенсивности $I$ полосы излучения фотолюминесценции от концентрации носителей заряда для пятикомпонентных твердых растворов $\mathrm{In}_{x} \mathrm{Al}_{y} \mathrm{Ga}_{1-x-y} \mathrm{P}_{z} \mathrm{As}_{1-z} / \mathrm{GaAs:} 1$ - легирование Te, 2 - легирование $\mathrm{Zn}$, температура измерений $77 \mathrm{~K} ; 3$ - легирование $\mathrm{Ge}$, 300 K. 4 - спектр фотолюминесценции $I_{\mathrm{PL}}$ пятикомпонентной гетероструктуры $\operatorname{In}_{x} \mathrm{Al}_{y} \mathrm{Ga}_{1-x-y} \mathrm{P}_{z} \mathrm{As}_{1-z} / \mathrm{GaAs}$ при $77 \mathrm{~K} .5-$ распределение интенсивности излучения по толщине слоя $h$.

к уширению полосы люминесценции. Так, на рис. 4 представлены спектры (кривые $a, b$ ), соответствующие слоям, выращенным методом ЗПГТ, и спектры (кривые c) слоев, выращенных методом принудительного охлаждения раствора-расплава [18]. Выращивание слоев твердых растворов в режиме принудительного охлаждения раствора-расплава практически не позволяет получить однородные по составу (по толщине) слои, даже при толщинах на уровне единиц микрометров. Вследствие этого полуширина спектра фотолюминесценции твердых растворов $\mathrm{In}_{x} \mathrm{Al}_{y} \mathrm{Ga}_{1-x-y} \mathrm{P}_{z} \mathrm{As}_{1-z}$, выращенных в режиме принудительного охлаждения раствора-расплава, составляла не менее $4 k T$. Кристаллизация слоев материала методом ЗПГТ с подпиткой позволяла выращивать однородные по составу твердые растворы и уменьшать полуширину спектральной полосы до уровня (2-3)kT (рис. 4).

Зависимость интенсивности фотолюминесценции слоев пятикомпонентных твердых растворов, легированных различными примесями, от концентрации носителей (рис. 5) проявляется только при $n, p>2 \cdot 10^{18} \mathrm{~cm}^{-3}$, так как в диапазоне $n, p=10^{17}-2 \cdot 10^{18} \mathrm{~cm}^{-3}$ время жизни неосновных носителей определяется временем излучательной рекомбинации. В области $n, p>2 \cdot 10^{18} \mathrm{~cm}^{-3}$ снижение эффективности фотолюминесценции обусловлено вкладом безызлучательных центров рекомбинации.

Исследования спектров фотолюминесценции пятикомпонентных гетероструктур с эпитаксиальным слоем постоянного состава показали высокую интенсивность краевого излучения. При этом полуширина полосы краевого излучения в зависимости от состава менялась в пределах 20-50мэВ, что говорит о высоком кристаллическом совершенстве получаемых структур. Для иллюстрации на рис. 5 (кривая 4) представлен типичный спектр фотолюминесценции гетероструктуры $\mathrm{In}_{x} \mathrm{Al}_{y} \mathrm{Ga}_{1-x-y} \mathrm{P}_{z} \mathrm{As}_{1-z} / \mathrm{GaAs}$ постоянного состава.

Ширина полосы излучения определяется в основном кристаллическим качеством слоя. В случае трехкомпонентных слоев дефектность структуры однозначно определяется химическим составом или величиной ширины запрещенной зоны $E_{g}$, поскольку чем сильнее состав слоя отличается от состава подложки, тем больше разность параметров решетки на гетерогранице. В четверных системах наличие дополнительной химической степени свободы позволяет согласовывать параметры решетки на гетерогранице и ширину спектральных полос фотолюминесценции, определяющуюся прежде всего рассогласованием по КТР, причем чем больше разность запрещенных зон слоя и подложки $\Delta E_{g}$, тем сильнее такое рассогласование и шире полоса излучения. В пятикомпонентных структурах может устраняться рассогласование и по КТР.

На рис. 6 представлены результаты исследований распределения плотности дислокаций по толщине различных гетероструктур, $N_{d}(h)$. Видно, что плотность дислокаций одинакова во всех точках однородного по

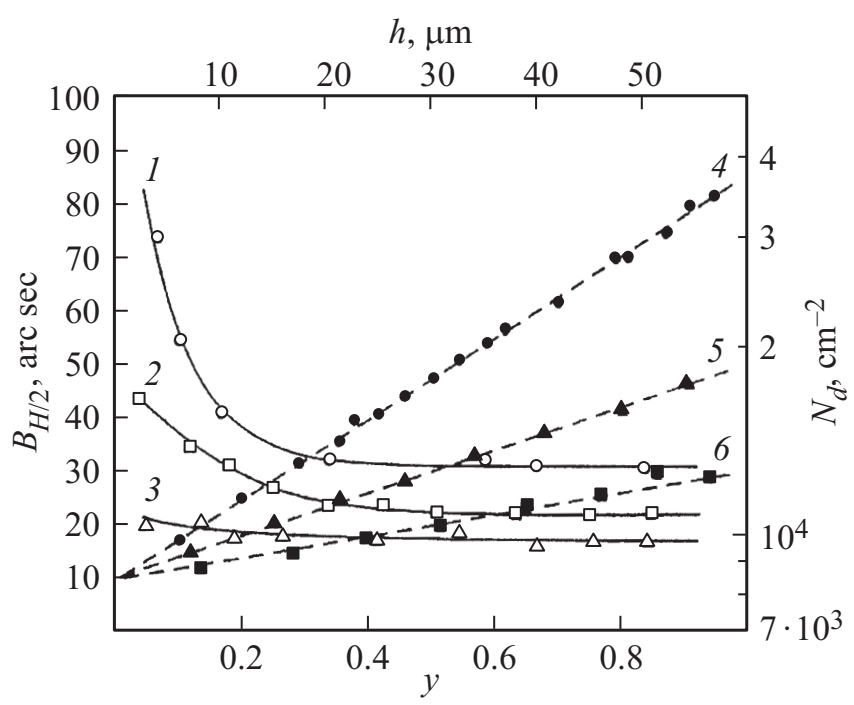

Рис. 6. Распределение плотности дислокаций $N_{d}$ по толщине слоев $(h) \mathrm{In}_{x} \mathrm{Al}_{y} \mathrm{Ga}_{1-x-y} \mathrm{P}_{z} \mathrm{As}_{1-z}(1-3$, правая и верхняя оси) и изменение ширины кривых качания на половине высоты $\left(B_{H / 2}\right)$ от концентрации алюминия $y(4-6$, левая и нижняя оси) для различных составов: $1-x=0, y=0.35, z=0 ; 2-$ $x=0, y=0.35, z=0.05 ; 3-x=0.08, y=0.35, z=0.05$; $4-x=0, y=0.35, z=0 ; 5-x=0, y=0.35, z=0.05$; $6-x=0.08, y=0.35, z=0.05$. (1-6) - гетероструктуры $\mathrm{In}_{x} \mathrm{Al}_{y} \mathrm{Ga}_{1-x-y} \mathrm{P}_{z} \mathrm{As}_{1-z} / \mathrm{GaAs}$ выращенные при одних и тех же технологических параметрах процесса ЗПГТ: $T=1133 \mathrm{~K}$, $l=300$ мкм, $G=30 \mathrm{~K} / \mathrm{cм}$. 
составу слоя твердого раствора (кривые 1-3), кроме участков вблизи гетерограницы. Плотности дислокаций в слое и подложке обычно не совпадают, причем в слое на границе с подложкой плотность дислокаций превышает таковую в слое и подложке. Эти факты указывают на отсутствие определяющей роли механизма прорастания дислокаций из подложки в слой. Такой характер распределения плотности дислокаций по толщине свидетельствует о том, что при больших значениях скачка состава на границе 〈трехкомпонентный слой $\left.\mathrm{Al}_{y} \mathrm{Ga}_{1-y} \mathrm{As}\right\rangle$ - $\langle$ бинарная подложка GaAs〉 (кривая 1) гетеропереход оказывается под действием напряжений, определяющихся различием параметров решетки $\Delta a$ и КТР $\Delta \alpha, \sigma_{\Delta a}+\sigma_{\Delta \alpha}$. Измерения ширины линий качания $\left(B_{H / 2}\right)$, проведенные на косых шлифах гетероструктур $\mathrm{Al}_{y} \mathrm{Ga}_{1-y} \mathrm{As} / \mathrm{GaAs}$ (кривая 4), подтверждают данное предположение. Результаты измерения $B_{H / 2}$ для слоев твердых растворов $\mathrm{In}_{x} \mathrm{Al}_{y} \mathrm{Ga}_{1-x-y} \mathrm{P}_{z} \mathrm{As}_{1-z}$ представлены на рис. 6 кривыми 4,5 для различных значений $x, y, z$ соответственно. Видно, что кристаллическое качество структуры ухудшается с увеличением концентрации алюминия на гетерогранице. Изменение качества прилегающей к гетерогранице области подложки с увеличением концентрации $\mathrm{Al}$ объясняется влиянием напряжений в гетеропереходе на подложку. Действительно, вследствие различия КTP GaAs и $\mathrm{AlGaAs}$ значение $\Delta a$ на границе гетероперехода при температуре кристаллизации эпитаксиального слоя меньше, чем при комнатной температуре. Поэтому после охлаждения до комнатной температуры гетеропереход (кривая 4) оказывается в напряженном состоянии. На рентгеновских топограммах косых шлифов гетероструктур в рефлексах для твердых растворов $\mathrm{Al}_{y} \mathrm{Ga}_{1-y} \mathrm{As}(y>0.4)$ или $\mathrm{GaAs}$ всегда наблюдались области протяженностью 1 мкм, имеющие контраст, отличный от контраста для слоя, и распространяющиеся по обе стороны от гетерограницы. При этом средний размер температурных пятен возрастает с увеличением разности периода решетки на гетероструктуре. Следовательно, такие пятна представляют собой дефекты структуры, связанные с различием в параметрах решетки, сопрягающихся на гетерогранице подложки и эпитаксиального слоя. Наблюдения гетероструктур $\mathrm{Al}_{y} \mathrm{Ga}_{1-y} \mathrm{As} / \mathrm{GaAs}$ в проходящем свете с помощью инфракрасного микроскопа МИК-4 подтвердили существование таких дефектов. Увеличение концентрации компонентов и, следовательно, $\Delta a$, приводит к появлению отдельных крупных дефектов, а начиная с $y>0.5$ для всех указанных гетероструктур - к образованию дефектного слоя. Исследования показали, что упругие напряжения концентрируются в области $\sim 10$ мкм по обе стороны гетерограницы и отсутствуют в объеме слоя, причем их величина в подложке и слое практически одинакова и зависит от состава твердого раствора. Проведенные оценки уровня упругих напряжений вблизи гетероперехода по расчетам с использованием соответствующих констант фотоупругости для $\mathrm{Al}_{y} \mathrm{Ga}_{1-y} \mathrm{As} / \mathrm{GaAs}$ дают значения, не превышающие $1.8 \cdot 10^{7}$ Па. Понизить на-

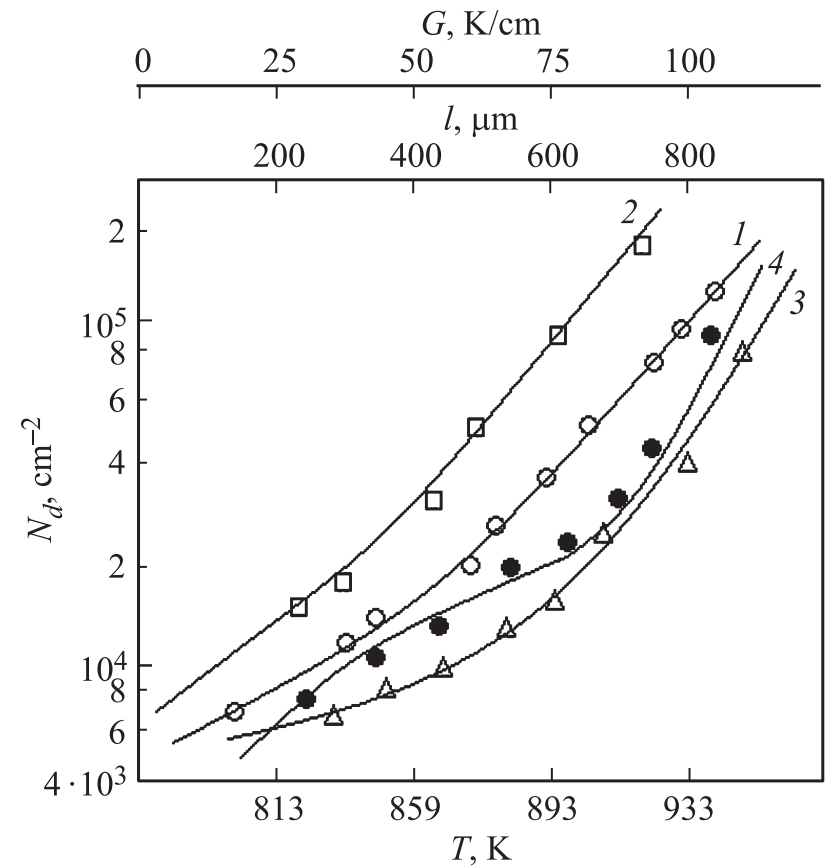

Рис. 7. Зависимость плотности дислокаций $N_{d}$ в эпитаксиальных слоях твердого раствора $\mathrm{In}_{x} \mathrm{Al}_{y} \mathrm{Ga}_{1-x-y} \mathrm{P}_{z} \mathrm{As}_{1-z}$ от толщины зоны $l(1,2)$, температуры $T(3)$ и градиента температуры $G(4)$ при $x=0.08, y=0.35, z=0.05$. (1,2) $G=20 \mathrm{~K} / \mathrm{cm}, \quad T=973 \mathrm{~K} ; 3-G=20 \mathrm{~K} / \mathrm{cm}, \quad l=300$ мкм; $4-l=300$ мкм, $T=973 \mathrm{~K}$. Концентрация дислокаций в подложке $N_{d}^{\text {sub }} \approx 3 \cdot 10^{3}(1), 2 \cdot 10^{4}(2), 3 \cdot 10^{3}(3), 2 \cdot 10^{3} \mathrm{~cm}^{-2}(4)$.

пряженное состояние гетероперехода можно уменьшением $\Delta a$ за счет введения четвертого компонента $(\mathrm{P})$ в $\mathrm{Al}_{y} \mathrm{Ga}_{1-y} \mathrm{As}$ (рис. 6, кривая 5) и In, P (рис. 6, кривая 6). Результаты измерений плотности дислокаций по толщине слоев четверных твердых растворов $\mathrm{Al}_{y} \mathrm{Ga}_{1-y} \mathrm{As}_{1-z} \mathrm{P}_{z}$ (рис. 6, кривая 2) показали, что дефектная переходная область значительно уменьшалась. Введение четвертого компонента уменьшает уровень остаточных напряжений до $0.5 \cdot 10^{7}$ Па в гетероструктурах $\mathrm{Al}_{0.35} \mathrm{Ga}_{0.65} \mathrm{As}_{0.95} \mathrm{P}_{0.05} / \mathrm{GaAs}$. Следовательно, введение четвертого компонента значительно уменьшает напряжения путем обеспечения решеточного согласования слоя и подложки при температурах эпитаксии. Однако дефектность гетерограницы даже для изопериодических составов четверных твердых растворов сохраняется довольно большой из-за различия КТР сопрягающихся слоя и подложки, она может быть снижена при переходе к пятикомпонентному раствору (рис. 6, кривая 3).

Влияние на кристаллическое качество эпитаксиальных гетероструктур в процессе ЗПГТ оказывают толщина зоны $(l)$, температура $(T)$ и ее градиент $(G)$. На рис. 7 приведены зависимости $N_{d}(l)$ (кривые 1,2). Возрастание $N_{d}$ с $l$ связано с проявлением концентрационного переохлаждения, которое для ЗПГТ растет с увеличением $l[12]$. Концентрационное переохлаждение расплава вызывает на фронте кристаллизации опреде- 
ленную нестехиометрию расплава. В этом случае возникает захват растущим кристаллом капель жидкой фазы. При понижении температуры капли расплава кристаллизуются, а избыток металлических атомов образует инородные включения. Кристаллизация захваченных капель расплава сопровождается появлением в кристалле значительных внутренних напряжений, дополнительной генерацией дислокаций. Непосредственно вблизи включений образуются дислокационные розетки, состоящие из большого числа дислокаций. При рентгеновских исследованиях эпитаксиальных слоев InAlGaPAs с включениями обнаружены большие значения разориентации (до $80^{\prime \prime}$ ) и резкое ослабление эффекта аномального прохождения рентгеновских лучей. Кроме того, кривые качания в этом случае имели по несколько максимумов.

Плотность дислокаций существенно зависит от температуры $T$ (рис. 7, кривая 3 ) и ее градиента $G$ (рис. 7, кривая 4$)$. Видно, что с увеличением $T$ и $G$ кристаллическое качество гетероструктур ухудшается и $N_{d}$ более резко увеличивается (при $T>893 \mathrm{~K}$ и $G>80$ град/см). Это связано с нарушением при таких величинах температуры и градиента температуры стабильности фронта кристаллизации, вследствие чего возникают отклонения состава от стехиометрического из-за несоответствия скоростей кристаллизации и растворения на границах жидкой зоны. При кристаллизации из нестехиометрического расплава эпитаксиальная пленка будет содержать большую концентрацию межузельных атомов III группы (Ga или In в случае InAlGaPAs) и вакансий атомов V группы (As), являющихся равновесными при высокой температуре. Кроме того, при $T>893 \mathrm{~K}$ и $G>80$ град/см значительно увеличивается скорость роста, что приводит к дополнительному захвату кристаллов избыточных межузельных атомов. В связи со стремлением кристалла к локальному совершенству вакансии Al или P (обладающие большими коэффициентами диффузии) будут стекать как на дислокации, так и на избыточные атомы III группы, образуя микровключения.

В гетероструктурах на основе четырехкомпонентных твердых растворов, в которых параметры решеток сопрягающихся материалов при температурах эпитаксии совпадают, основным источником дефектности гетерограниц являются термические напряжения, обусловленные различием КТР. Термические напряжения снимаются введением пятого компонента. На рис. 6 представлены распределения плотности дислокаций по толщине слоев ПТР $\operatorname{In}_{x} \mathrm{Al}_{y} \mathrm{Ga}_{1-x-y} \mathrm{P}_{z} \mathrm{As}_{1-z} / \mathrm{GaAs}$ (кривая 3). Видно, что введение небольшой добавки In $(x<0.1)$ практически полностью сводит на нет переходную дефектную область.

Следовательно, в пятикомпонентных твердых раствоpax из-за совмещения периодов решетки и КТР можно получать „идеальную“ гетерокомпозицию на основе ПТР, т.е. гетерокомпозицию, в которой отсутствуют и дислокации несоответствия, и напряжения. Однако в таких случаях важную роль играет качество подложечного материала, так как основной вклад в дефектооб- разование в пятикомпонентных гетероструктурах будет вносить наследование дефектов из подложки.

При этом в слое $\operatorname{In}_{x} \mathrm{Al}_{y} \mathrm{Ga}_{1-x-y} \mathrm{P}_{z} \mathrm{As}_{1-z}$ с высокой плотностью дислокаций, $N_{d}>1 \cdot 10^{5} \mathrm{~cm}^{2}$, наблюдаются малоугловые границы с углами разориентации между граничащими участками до $0.2^{\circ}$. Такая разориентация обусловлена возрастанием плотности разориентированных зародышей на шероховатой поверхности, что ведет в свою очередь к перемещению и выстраиванию дислокаций в процессе роста слоев.

Следовательно, при эпитаксии пятикомпонентных твердых растворов требования к качеству подложечного материла значительно возрастают.

\section{5. Заключение}

Изопараметрические гетероструктуры InAlGaPAs/ GaAs, контролируемые по толщине, составу и кристаллическому качеству, могут быть выращены в поле температурного градиента из жидкой фазы. Однородное распределение компонентов по толщине достигается при использовании перекристализуемого источника InAlPAs.

Основными параметрами, определяющими качество поверхности, кристаллическое качество и люминесцентные свойства гетероструктур, являются толщина и состав жидкой зоны, температура и градиент температуры процесса ЗПГТ.

Пятикомпонентные гетероструктуры InAlGaPAs/GaAs имеют более широкий спектральный диапазон, высокое кристаллическое совершенство и лучшие люминесцентные характеристики в сравнении с соответствующими трех- и четырехкомпонентными гетероструктурами и поэтому более предпочтительны для высокоэффективных приборов, основанных на излучательной рекомбинации.

Работа выполнена в рамках государственного задания (грант № 16.4757.2017/8.9) а также при финансовой поддержке РФФИ в рамках научного проекта № 17-08-01206 A.

\section{Список литературы}

[1] В.Н. Лозовский, Л.С. Лунин. Пятикомпонентные твердые растворы соединений (новые материалы оптоэлектроники) (Ростов-н/Д., Изд-во СКНЦ ВШ, 1992).

[2] В.В. Кузнецов, Л.С. Лунин, В.И. Ратушный. Гетероструктуры на основе четверных и пятерных твердых растворов соединений $\mathrm{A}^{\mathrm{III}} \mathrm{B}^{\mathrm{V}}$. (Ростов-н/Д., Изд-во СКНЦ ВШ, 2003).

[3] Л.М. Долгинов, П.Г. Елисеев, И. Исмаилов. Итоги науки и техники. Радиотехника, 21, 3 (1980).

[4] C. Ma, M. Dech, L. Tarof, I. Yn. IEEE Trans. Electron Dev., 42 (5), 810 (1995).

[5] В.П. Хвостиков, Л.С. Лунин, В.В. Кузнецов. Письма ЖТФ, 29 (20), 33 (2003).

[6] Д.Л. Алфимова, Л.С. Лунин, М.Л. Лунина. Поверхность. Рентгеновские синхротронные и нейтронные исследования, 6, 103 (2014). 
[7] С.Н. Чеботарев, М.Л. Лунина, Д.Л. Алфимова. Наноструктуры $A^{\mathrm{IV}} B^{\mathrm{IV}}$ и $A^{\mathrm{III}} B^{\mathrm{V}}$ для устройств оптоэлектроники (Ростов-н/Д., Изд-во ЮНЦ РАН, 2014).

[8] С.Н. Чеботарев, В.В. Калинчук, Л.С. Лунин. Полупроводниковые наногетероструктуры с промехсточной подзоной (М., Изд-во Физматлит, 2016).

[9] Ж.И. Алфёров, В.М. Андреев, В.Д. Румянцев. ФТП, 38 (8), 937 (2004).

[10] Zh.I. Alferov, V.M. Andreev. V.D. Rumyantsev. In: Concentrator Photovoltaic, ed. by A. Luque and V. Andreev [Springer Ser. in Optical Sci., 130, 25 (2007)].

[11] В.М. Андреев, Л.М. Долгинов, Д.Н. Третьяков. Жидкостная эпитаксия в технологии полупроводниковых приборов (М., Изд-во Сов. радио, 1975).

[12] В.Н. Лозовский, Л.С. Лунин, В.П. Попов. Зонная перекристаллизация градиентом температуры полупроводниковых материалов (М., Изд-во Металлургия, 1987).

[13] Л.С. Лунин, А.В. Благин, Д.Л. Алфимова. Физика градиентной эпитаксии многокомпонентных полупроводниковых гетероструктур (Ростов-н/Д., Изд-во СКНЦ ВШ, 2008).

[14] Л.С. Лунин, И.А. Сысоев. Техника градиентной эпитаксии полупроводниковых гетероструктур электронной техники (Ростов-н/Д., Изд-во СКНЦ ВШ, 2008).

[15] В.Н. Лозовский, Л.С. Лунин, Т.А. Аскарян. Изв. вузов. Физика, 7, 41 (1989).

[16] В.Н. Лозовский, Л.С. Лунин, Т.А. Аскарян. Изв. вузов. Физика, 1, 59 (1989).

[17] В.В. Кузнецов, Е.А. Когновицкая, М.Л. Лунина, Э.Р. Рубцов. Журн. физ. химии, 85 (12), 1 (2011).

[18] S. Mukai, H. Jajima, S. Janagisawa, N. Kutsuwada. Appl. Phys. Lett., 44 (9), 904 (1984).

Редактор Л.В. Шаронова

\section{Growing and properties of isoparametric InAIGaPAs/GaAs heterostructures}

D.L. Alfimova ${ }^{1}$, L.S. Lunin ${ }^{\mathbf{1}, 2}$, M.L. Lunina ${ }^{1}$, D.A. Arustamyan ${ }^{2}$, A.E. Kazakova ${ }^{2}$,

S.N. Chebotarev ${ }^{\mathbf{1 , 2}}$

${ }^{1}$ Southern Scientific Center, Russian Academy of Sciences, 343006 Rostov-on-Don, Russia

${ }^{2}$ Platov South-Russian State Polytechnic University (NPI),

346428 Novocherkassk, Russia

Abstract The paper discusses growing process and properties of isoparametric InAlGaPAs/GaAs heterostructures. We have studied composition, structural quality and luminescent properties of the heterostructures. 